\title{
REHABILITATION MEDICINE IN EU/ROMANIA AS IT IS PERCEPTED BY RESIDENT DOCTORS (DREEM TEST)
}

\author{
Ioan-Sorin Stratulat ${ }^{1,2,3,4}$ \\ ${ }^{1}$ Associate Professor, Faculty of Medicine/ Dental medicine, University of Medicine and \\ Pharmacy "Gr. T. Popa" - Iasi, ${ }^{2}$ Chief Clinical, Medical Rehabilitation Clinic, C.F. Hospital \\ Iasi, ${ }^{3}$ Associate researcher, Faculty of Physics, Atmosphere Optics, Spectroscopy and Lasers \\ Laboratory "Alexandru Ioan Cuza" University of Iasi, ${ }^{4}$ Centre of Advanced Research in \\ Bionanoconjugates and Biopolymers
}

\author{
e-mail: \\ sorin.ioan.stratulat@gmail.com \\ dr_sorin_stratulat@yahoo.com
}

\begin{abstract}
Introduction: Rehabilitation is a complex activity, both medical and social, that involves professional education for the patient, family and medical personnel. This activity seeks to restore full functionality for patients, in order to ensure an almost normal life. Our goal was to measure the interest and assesment of resident doctors in Rehabilitation Medicine on their speciality and also on their social and educational life.

Material and methods: We have applied and validated the original "Dundee Ready Education Environment Measure (DREEM)" test in English, for the first time for residents. The DREEM test, implying questions and answers with multiple coefficients, was filled in anonymously. A total of 28 resident doctors have participated at the test, the results being distributed by year of practice.

Results: All Cronbach alpha correlation coefficients are significant $(>0.7)$ except the $5^{\text {th }}$ category. As regards the inter-item correlations (internal consistency) for each category, on our sample, the test has a very good overall reliability, but we have found some questions that are not significant for the final results. The test has its own interpretation guide, with four final possible results, in the range from 0 to 200 points. In our case, the total average score was 150.4 points, which places us on the borderline between the $3^{\text {rd }}$ and $4^{\text {th }}$ category: 101-150 points / 151-200 points (between „More positive than negative” and “Excellent”).

Discussions: The test showed that the residents have approved the courses and the clinical part comprising practical works. They showed interest in treatment methodologies, as well as in the idea of associating theoretical and practical training, considering it necessary for their future profession. The DREEM test showed that the assessment and treatment of various pathologies approached through medical rehabilitation perspective is a matter of interest to all the resident doctors from all years of practice.

Conclusions: Periodic testing of resident's perception proves particularly useful for identifying the deficiencies, which may arise during the teaching process. This can be a significant instrument to continuously respond to the raised common issues, solving them efficiently. As a student-teacher partnership, modern training cannot ignore the practical needs of resident doctors, that are in the need of permanently improving their skills, by combining theoretical training with specialized courses and practical work, all necessary for their profession.
\end{abstract}

Key words: Medical Rehabilitation, resident doctors, professional training, DREEM test. 